\title{
ANISOTROPY OF THE SURFACE OF CARBON MATERIALS
}

\author{
Yurov V.M. ${ }^{1}$, Goncharenko V.I. ${ }^{2,3}$, Oleshko V.S. ${ }^{2}$, Sha Minggong ${ }^{4}$ \\ ${ }^{1}$ E.A. Buketov Karaganda University, Karaganda, Kazakhstan, exciton@list.ru \\ 2 Moscow Aviation Institute (National Research University), Moscow, Russia, ovs_mai@mail.ru \\ 3 V.A. Trapeznikov Institute of Control Sciences of Russian Academy of Sciences, Moscow, Russia \\ ${ }^{4}$ Northwestern Polytechnical University (NPU), School of Civil Aviation, Beilin District, Xi'an Shaanxi, P.R. China, \\ Shamg2020@nwpu.edu.cn
}

In this work, a model of the surface layer of perfect single crystals is used and the role of surface energy in physical processes occurring in the region of nanosized carbon materials is clarified. Of these, diamond, graphite, carbyne and fullerenes have been investigated. The thickness of the surface layer of diamond with cubic symmetry is $8.2 \mathrm{~nm}$ and is a nanostructure. The average size of the synthesized nanodiamond is of the order of $\sim 8 \mathrm{~nm}$. The value of the surface energy ohkl calculated by us along the diamond planes (100), (110), and (111) is in good agreement with experiment and other calculations. The thickness of the surface layer of graphite along the a axis is equal to $R(I)_{a}=8.0 \mathrm{~nm}$ and also represents a nanostructure. But along the $c$ axis we have a layer thickness of about $1.5 \mathrm{~nm}$ and the number of monolayers is only 2. On this c axis, graphite can be created a monolayer by turning it into graphene. The $\sigma_{h k l}$ value calculated by us along the a and c planes of graphite is 25957 and 5515 $\mathrm{mJ} / \mathrm{m}^{2}$, respectively. Carbines represent a polymeric polyyne or cumulene chain composed of sp-hybridized carbon atoms. If we imagine that the thickness of the surface layer of carbyne is stretched into a one-dimensional chain along the $c$ axis, then the length of this chain is up to $200 \mathrm{~nm}$ for $\alpha$-carbyne. The thickness of the surface layer of fullerenes significantly exceeds the thickness of the surface layer of pure metals. The surface energy of fullerenes $\sigma_{h k l}$ increases with an increase in the number of carbon atoms $C_{36} \rightarrow C_{96}$. It also changes in the series $(111) \rightarrow(100) \rightarrow(110)$.

Keywords: diamond, graphite, carbyne, fullerenes, nanostructures, surface layer thickness, surface energy, anisotropy.

\section{Introduction}

This work is a continuation of works [1-3], where for the first time a model of the surface layer of perfect single crystals was constructed and the role of surface energy in physical processes occurring in the nanoscale region was clarified. Calculations of the surface energy will be carried out according to the formula derived under the assumption that there are no first-order phase transitions in these substances up to their melting point, which for crystals with a body-centered (bcc) and face-centered (fcc) cubic structure is given by the relations [4], where $\mathrm{Z}$ is the number of formula units of the unit cell, $1_{\mathrm{hkl}}$ is the thickness of the first coordination sphere in the [hkl] direction, and is the lattice constant:

$$
\begin{aligned}
& \operatorname{Im} 3 \mathrm{~m}, \mathrm{Z}=2 ; 1_{100}=\mathrm{a} ; 1_{110}=\mathrm{a} \sqrt{2} ; 1_{111}=\mathrm{a} / \sqrt{3}, \\
& \mathrm{Fd} 3 \mathrm{~m}, \mathrm{Z}=4 ; 1_{100}=\mathrm{a} ; 1_{110}-\mathrm{a} / \sqrt{2} ; 1_{111}=2 \mathrm{a} / \sqrt{3} .
\end{aligned}
$$
relations:

In works $[5,6]$ for the thickness of the surface layer $R$ and surface energy $\sigma$, we obtained the following

$$
\begin{aligned}
& \mathrm{R}(\mathrm{I})=\left[\mathrm{kg} / \mathrm{mol} \cdot \mathrm{m}^{3} / \mathrm{kg} \cdot \mathrm{m}^{-2}\right] \cdot 0,24 \cdot 10^{-9} \cdot \mathrm{M} / \rho, \mathrm{nm} \\
& \mathrm{R}(\mathrm{I})_{\mathrm{x}=\mathrm{a}}=\left[\mathrm{m}^{3} \cdot \mathrm{m}^{-2}\right] \cdot 0,54 \cdot 10^{-11} \cdot \mathrm{x}(\mathrm{a})^{3}, \mathrm{~nm} \\
& \mathrm{R}(\mathrm{I})_{\mathrm{y}=\mathrm{b}}=\left[\mathrm{m}^{3} \cdot \mathrm{m}^{-2}\right] \cdot 0,54 \cdot 10^{-11} \cdot \mathrm{y}(\mathrm{b})^{3}, \mathrm{~nm} \\
& \mathrm{R}(\mathrm{I})_{\mathrm{z}=\mathrm{c}}=\left[\mathrm{m}^{3} \cdot \mathrm{m}^{-2}\right] \cdot 0,54 \cdot 10^{-11} \cdot \mathrm{z}(\mathrm{c})^{3}, \mathrm{~nm} \\
& \sigma_{\mathrm{a}}=\left[\mathrm{mJ} / \mathrm{m}^{2} \cdot \hat{\mathrm{E}} / \hat{\mathrm{E}}\right] \cdot 10^{-3} \cdot \mathrm{T}_{\mathrm{m}} \cdot \mathrm{R}_{\mathrm{a}}(\mathrm{I}) / \mathrm{R}(\mathrm{I}), \mathrm{mJ} / \mathrm{m}^{2} \\
& \sigma_{\mathrm{b}}=\left[\mathrm{mJ} / \mathrm{m}^{2} \cdot \hat{\mathrm{E}} / \hat{\mathrm{E}}\right] \cdot 10^{-3} \cdot \mathrm{T}_{\mathrm{m}} \cdot \mathrm{R}_{\mathrm{b}}(\mathrm{I}) / \mathrm{R}(\mathrm{I}), \mathrm{mJ} / \mathrm{m}^{2} \\
& \sigma_{\mathrm{c}}=\left[\mathrm{mJ} / \mathrm{m}^{2} \cdot \hat{\mathrm{E}} / \hat{\mathrm{E}}\right] \cdot 10^{-3} \cdot \mathrm{T}_{\mathrm{m}} \cdot \mathrm{R}_{\mathrm{c}}(\mathrm{I}) / \mathrm{R}(\mathrm{I}), \mathrm{mJ} / \mathrm{m}^{2}
\end{aligned}
$$


Here $\mathrm{M}$ is the molar mass of the crystal, $\rho$ is its density, a, b, c are the unit cell parameters of the crystal, and $\mathrm{Tm}$ is its melting point. In this work, we investigate the thickness of the surface layer and the surface energy of carbon materials.

\section{Diamond}

In general, 11 varieties have been identified among crystals and polycrystalline formations of diamond [7]. We will consider only the single crystals shown in Figure 1.
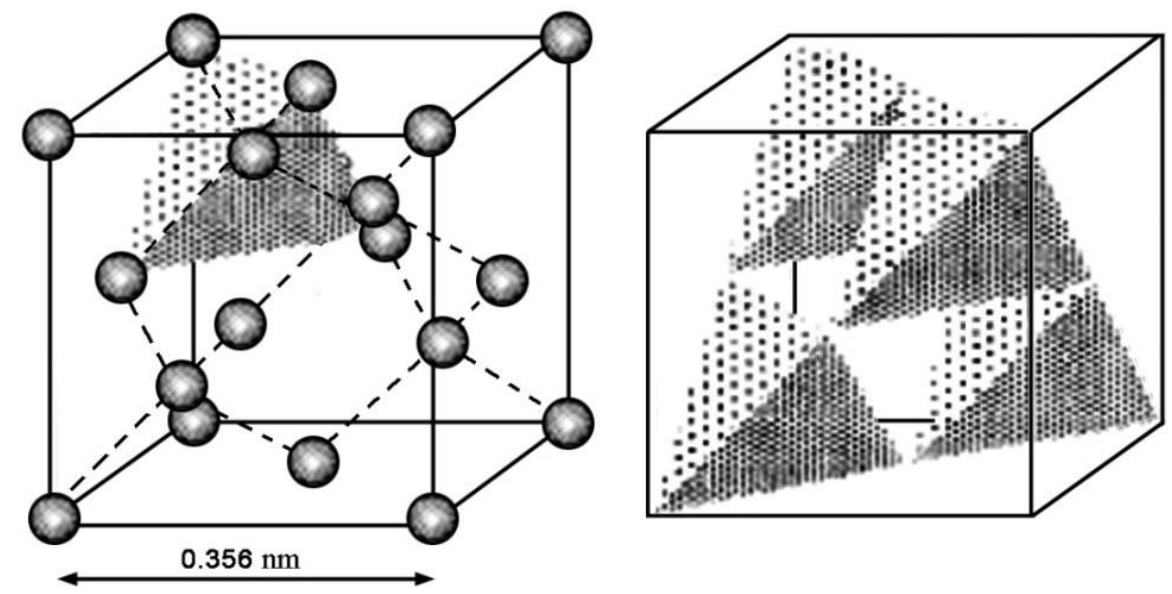

Fig.1. The structure of diamond (allotropic form of carbon C): "ball" model (left) and polyhedral model (right) [8].

Of all the proposed structural modifications of diamond, the structure (allotropic form of carbon C), which belongs to the holohedral class Oh, having the symmetry of the Fedorov space group Oh7-Fd3m, is most confirmed theoretically and experimentally. Lattice parameter at a temperature of $25^{\circ} \mathrm{C}$ and $\mathrm{p}=1 \mathrm{~atm}$. is equal to $\mathrm{a}=3.57 \AA$ [9], and the melting point $\mathrm{T}_{\mathrm{m}}=3973-4273 \mathrm{~K}$, density $\rho=3.47-3.55\left(\mathrm{~g} / \mathrm{cm}^{3}\right)$, molar mass $\mathrm{M}=12.01(\mathrm{~g} / \mathrm{mol})$.

The structural cell of a diamond crystal is two cubes with a period of $0.356 \mathrm{~nm}$, shifted relative to each other along the diagonal of the cube [9], then instead of (1) one should write:

$$
\begin{aligned}
& \sigma \approx 2 \cdot 10^{-3} \mathrm{~T}_{\mathrm{m}} \\
& \mathrm{Fd} 3 \mathrm{~m}, \mathrm{Z}=4 ; 1_{100}=\sigma ; 1_{110}-\sigma / \sqrt{2} ; 1_{111}=\sigma / \sqrt{3}
\end{aligned}
$$

Using (2) and (3), we calculate the surface energy anisotropy (table 1).

\begin{tabular}{|c|c|c|c|c|c|c|c|}
\hline Diamond & (hkl) & Structure & $\mathrm{T}_{\mathrm{m}}, \mathrm{K}$ & $\mathrm{R}(\mathrm{I}), \mathrm{nm}$ & $\begin{array}{c}\sigma_{\mathrm{hkl}} \\
\text { by }(1), \mathrm{mJ} / \mathrm{m}^{2}\end{array}$ & $\begin{array}{c}\sigma_{\mathrm{hkl}} \\
\text { by [10], } \mathrm{mJ} / \mathrm{m}^{2}\end{array}$ & $\begin{array}{c}\sigma_{\mathrm{hkl}} \\
\text { by }[11], \mathrm{mJ} / \mathrm{m}^{2}\end{array}$ \\
\hline \multirow{3}{*}{$\mathrm{C}$} & 100 & \multirow{3}{*}{$\mathrm{Fd} 3 \mathrm{~m}$} & \multirow{3}{*}{4273} & \multirow{3}{*}{$\begin{array}{c}8,2 \\
(23)\end{array}$} & 8546 & 9100 & - \\
\hline & 110 & & & & 6104 & 6274 & - \\
\hline & 111 & & & & 5027 & 5270 & $4999 \pm 355$ \\
\hline
\end{tabular}

Table 1. Anisotropy of the surface energy of diamond

Let us now analyze Table 1 . The thickness of the surface layer of diamond $\mathrm{R}(\mathrm{I})=8.2 \mathrm{~nm}$, that is, this layer is a nanostructure, which contains 23 monolayers of diamond. In this layer with atoms of pure metals and non-metals, there is a reconstruction and relaxation associated with the rearrangement of the surface [13]. The size effects in the R(I) layer are determined by the entire collective of atoms in the system (collective processes). Almost classic dimensional effects are observed only in nanoparticles and nanostructures [1-3]. Experimentally, they can be observed in very pure single crystals with grazing incidence of $\mathrm{X}$-ray radiation, when the angle of incidence is equal to or less than the critical angle of total internal reflection. 
The value of $\sigma_{\mathrm{hkl}}$ calculated by us for the planes (100), (110) and (111) is compared with the results of [10] and [11]. The calculations are based on the work of Harkins [10], published back in 1942. It is performed theoretically on the basis of Gibbs thermodynamics. Assuming the C-C bond energy in diamond equal to $90 \mathrm{kcal} / \mathrm{mol}$, and the cohesion energy of diamond equal to twice the surface energy, he obtained the $\sigma_{\mathrm{hkl}}$ values presented in Table 1 . The results of the experimental measurement of the surface energy of diamond by the Griffiths method were carried out in 2017 in [11] along the (111) plane and are also presented in Table 1. This experimental value of the surface energy of diamond is very close to the value of $\sigma_{\mathrm{hkl}}$ obtained by us (Table 1). Theoretical estimates of the surface energy of diamond for the (100) plane were carried out in many works $\left(\mathrm{mJ} / \mathrm{m}^{2}\right): 9400$ [12], 6513 [13], 6118 [14].

\section{Graphite}

Graphite is a unique native mineral, an allotropic modification of the element carbon, which is the most stable in the earth's crust. Graphite has that unique set of qualities that make it indispensable for problems in nuclear physics and power engineering [15]. The hexagonal lattice of graphite belongs to the space group $\mathrm{C} 6 / \mathrm{mmc}^{-\mathrm{D}^{4}}{ }_{6 \mathrm{~h}}$ with four atoms per unit cell. The parameter a of the hexagonal cell is $2.46 \AA$, the parameter c $=6.74 \AA$, the theoretical density of such a crystal is $2.267 \mathrm{~g} / \mathrm{cm}^{3}$. In each plane, carbon atoms form a network of regular hexagons with an atom spacing of $1.42 \AA$. The bonds within the layers, which have a covalent nature, represent trigonal hybrids (2s, 2px, 2py) (Figure 2) [8]. Melting temperature range $\mathrm{T}_{\mathrm{m}}=4218-4163$ K.

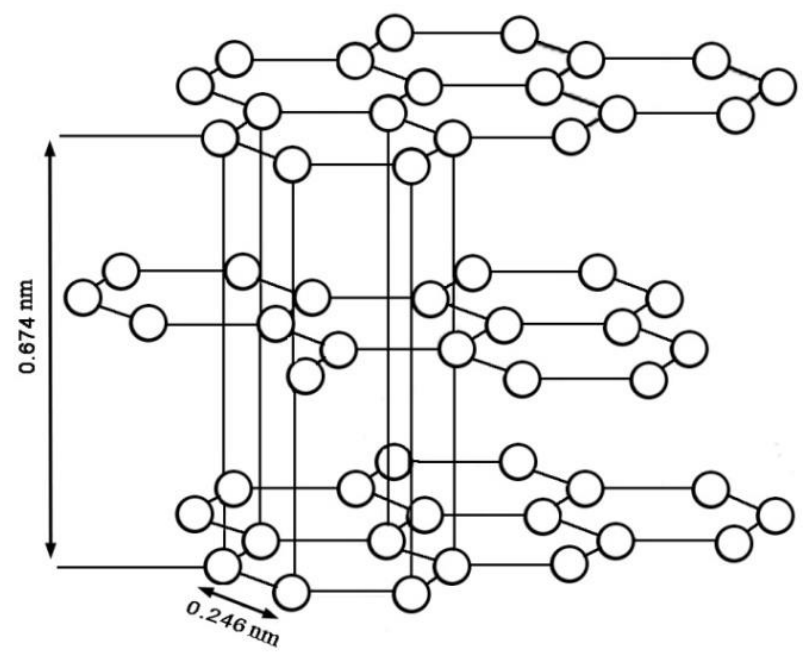

Fig. 2. Hexagonal graphite C [8].

Let us determine the thickness of the surface layer of hexagonal graphite and the anisotropy of its energy. The thickness of the surface layer of diamond $\mathrm{R}(\mathrm{I})=8.2 \mathrm{~nm}$, which almost coincides with $\mathrm{R}(\mathrm{I})_{\mathrm{a}}=$ $8.0 \mathrm{~nm}$ and also represents a nanostructure. But along the $\mathrm{c}$ axis we have a layer thickness of about $1.5 \mathrm{~nm}$ and the number of monolayers is only 2. On this $c$ axis, graphite can be created a monolayer by turning it into graphene.

To determine the free surface energy of pyrographite by the Gilman method in a vacuum, a special installation was constructed. The experiments were carried out with pyrographite grade P2100V with the maximum sample thickness. The free surface energy of pyrographite of the indicated grade was found to be $\sigma_{\mathrm{c}}=5000 \mathrm{~mJ} / \mathrm{m}^{2}$ [11], which is close to that obtained by us in Table 2 .

Table 2. Thickness of the surface layer and anisotropy of the surface energy of graphite

\begin{tabular}{|c|c|c|c|c|c|}
\hline Graphite & Structure & $\mathrm{R}(\mathrm{I})_{\mathrm{a}}, \mathrm{nm}$ & $\mathrm{R}(\mathrm{I})_{\mathrm{c}}, \mathrm{nm}$ & $\sigma_{\mathrm{a}}, \mathrm{mJ} / \mathrm{m}^{2}$ & $\sigma_{\mathrm{c}}, \mathrm{mJ} / \mathrm{m}^{2}$ \\
\hline $\mathrm{C}$ & $\mathrm{C}^{2} / \mathrm{mmc}^{4} \mathrm{D}_{6 \mathrm{~h}}$ & $\begin{array}{c}8,0 \\
(33)\end{array}$ & $\begin{array}{c}1,7 \\
(2)\end{array}$ & 25957 & 5515 \\
\hline
\end{tabular}




\section{Carbyne}

Carbines represent a polymeric polyyne $(-\mathrm{C} \equiv \mathrm{C}-)_{\mathrm{m}}$ or cumulene $(=\mathrm{C}=\mathrm{C}=)_{\mathrm{n}}$ chain, consisting of carbon atoms in sp-hybridization (Fig. 3a, b). Polymer chains in carbyne crystals are packed in the form of hexagons along the (001) face. The presence of bends in the chains causes displacement of the layers (Fig. 3c).
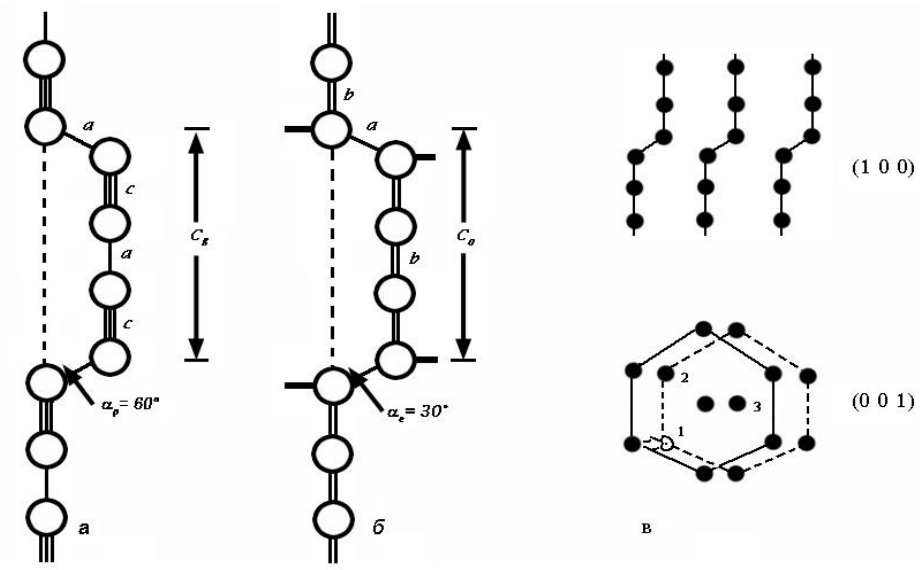

Fig. 3. Heimann's model of $\alpha$-carbyne (a) and $\beta$-carbyne (b); c - two-layer model [16].

The hexagonal cell of the $\alpha$-carbyne crystal has the following crystal lattice parameters: $a=b=0.894$ $\mathrm{nm}$ and $c=1.536 \mathrm{~nm}$; for $\beta$-carbyne $-a=b=0.824 \mathrm{~nm}$ and $c=0.768 \mathrm{~nm}$ [17]. The density of carbyne crystals is $1.9-2.0 \mathrm{~g} / \mathrm{cm}^{3}$. The melting point is about $3970 \mathrm{~K}$. Using these data, we estimate the thickness of the surface layer and the anisotropy of the surface energy of the carbine (formula 2). Here R(I) $=36$, since the molar mass of carbon in the unit cell is $M=12 \times 6=72$, where 6 is a six-atomic chain [18], and $\rho \approx 2.0$ $\mathrm{g} / \mathrm{cm}^{3}$.

Table 3. Surface layer thickness and surface energy anisotropy of carbyne

\begin{tabular}{|c|c|c|c|c|c|}
\hline Carbin & Structure & $\mathrm{R}(\mathrm{I})_{\mathrm{a}}, \mathrm{nm}$ & $\mathrm{R}(\mathrm{I})_{\mathrm{c}}, \mathrm{nm}$ & $\sigma_{\mathrm{a}}, \mathrm{mJ} / \mathrm{m}^{2}$ & $\sigma_{\mathrm{c}}, \mathrm{mJ} / \mathrm{m}^{2}$ \\
\hline $\mathrm{C}$ & $\alpha$-carbin & 38,6 & 196,7 & 4257 & 21692 \\
& & $(43)$ & $(128)$ & 3330 & 4411 \\
\hline $\mathrm{C}$ & $\beta$-carbin & 30,2 & $(52)$ & & \\
\hline
\end{tabular}

The thickness of the surface layer of carbyne differs significantly from those for diamond and graphite, but closer to carbon materials like fullerenes, which we will discuss below. The anisotropy of the surface energy of carbines, which also have a hexagonal crystal cell, does not differ much from the surface energy of grphites.

\section{Fullerene}

Fullerene was discovered in 1985 by G. Kroto (Great Britain), R. Curl, R. Smelli (USA), for which they were awarded the Nobel Prize in 1996. A review of fullerenes for 15 years from 1991 to 2006 was carried out in [19]. The most recent monograph on the structure and stability of higher fullerenes is described in [20]. It discusses a completely new - molecular - form of carbon existence; these closed carbon clusters were able to capture and enclose within themselves individual atoms, several atoms, and even small molecules. All this is new and unusual from the point of view of theoretical chemistry and fundamental science in general.

Fullerenes are carbon clusters with an even, more than 20, number of carbon atoms forming three bonds with each other; atoms in fullerene molecules are located on the surface of a spheroid at the vertices of hexagons and pentagons. Examples of fullerenes are shown in Fig. 4 [21]. In [22], a relationship was found between the mass of the $\mathrm{C}_{\mathrm{cn}}$ fullerene molecule and the properties of fcc fullerites, such as: the sublimation 
energy, the distance between the centers of the nearest molecules, the Grüneisen parameter. compression modulus at zero pressure and temperature.

Based on the data of the correlation dependences, the parameters of the Mee-Lennard-Jones pair potential for the inter-fullerene interaction in fcc fullerites were reconstructed. On the basis of the obtained parameters of the potential, the properties of fullerites are calculated and good agreement with the data known from the literature is obtained. It is shown that at $n c<15-20$ crystals of fullerites $C_{c n}$ are unstable. At the same time, fullerites where nc $>100$ will have anomalously low surface energies, which should lead to fragmentation of nanoclusters from such large $\mathrm{Cnc}$ molecules. The parameters of the triple and critical points of fullerenes are estimated.
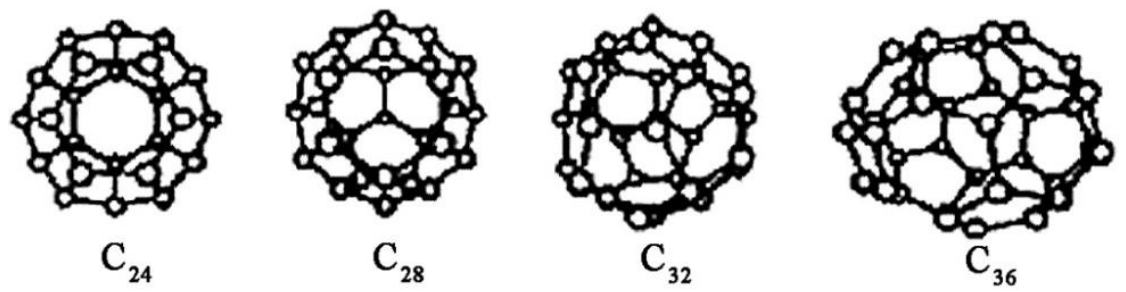

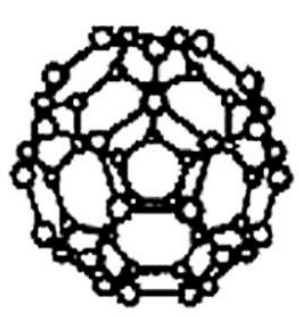

$\mathrm{C}_{50}$
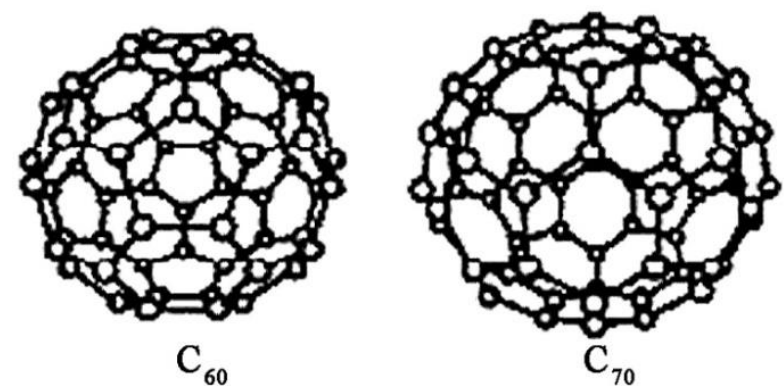

Fig. 4. Schemes of the structure of fullerenes [21]

The evolution of the parameters of the potential and the indicated properties with a change in the molecular weight of the fullerene has been studied. The parameters $\mathrm{T}_{\mathrm{m}}, \mathrm{M}, \rho$ for calculating $\mathrm{R}(\mathrm{I})$ and $\sigma_{\mathrm{hkl}}$ were taken by us from [22]. In addition, knowing the thickness of the surface layer $R(I)$ and the crystal lattice parameter $a$, one can estimate the number of monolayers that form the $\mathrm{R}(\mathrm{I})$ layer $(\mathrm{n}=\mathrm{R}(\mathrm{I}) / a)$. Thus, for gold and silicon, we showed [23] that the R(I) layer contains 3 monolayers of gold and 4 monolayers of silicon. The same order of magnitude in the R(I) layer contains the number of monolayers of pure metals. Table 4 shows that the thickness of the surface layer of fullerenes R(I) significantly exceeds the thickness of the surface layer of metals.

It follows from Table 4 that the thickness of the surface layer of fullerenes $\mathrm{R}(\mathrm{I})$ in $\mathrm{C}_{84}$ and $\mathrm{C}_{96}$ exceeds $100 \mathrm{~nm}$ according to Glater [24], which is characteristic of nanostructures. At $\mathrm{h} \approx 10 \mathrm{R}(\mathrm{I})$, a phase transition occurs in the surface layer of fullerenes. For example, in fullerene $\mathrm{C}_{60}$, the phase transition is due to the action of the forces of pair van der Waals interaction, which have a significant noncentral component due to the anisotropy of the electron density on the surface of molecules [25]. So at $2600 \mathrm{~K}$ the fcc lattice transforms into a simple cubic (PC) lattice. In the PS structure, there is the possibility of hindered rotations of molecules around ordered axes between two energetically nonequivalent orientational configurations: pentagons and hexagons. The surface energy of fullerenes $\sigma_{\mathrm{hkl}}$ increases with an increase in the number of carbon atoms $\mathrm{C}_{36} \rightarrow \mathrm{C}_{96}$. It also changes in the series (111) $\rightarrow(100) \rightarrow(110)$ (table 4).

\section{Carbon materials}

Carbon materials can be viewed as spatially cross-linked polymeric substances. In these compounds, carbon is tetravalent and is in one of three ground states corresponding to $\mathrm{sp}^{3}-\mathrm{sp}^{2}$ - and sp-hybridization of electrons. In a number of substances, carbon atoms are in different, including intermediate $\left(\mathrm{sp}^{\mathrm{m}}\right.$-), electronic states. To describe them, the most convenient classification (Figure 5) by the type of chemical bonds, based on the hybridization of electron orbitals of carbon atoms [26]. Let us now compare the results obtained by us, presented in tables 1-4. Table 1 shows that the thickness of the surface layer of diamond is $8.2 \mathrm{~nm}$ and is a nanostructure. That is, nanodiamonds are of interest. Detonation nanodiamonds were first synthesized in 1963 by the explosive decomposition of powerful mixtures of explosives with a negative oxygen balance in a 
non-oxidizing environment. Such diamonds are characterized by nanoscale particles, chemical resistance of the diamond core, and activity of the peripheral shell [27]. Moreover, as a result of detonation of a charge weighing $140 \mathrm{~kg}$ in an aqueous shell, particles of an average size of $\sim 8 \mathrm{~nm}$ were obtained (compare with Table 1)

Table 4. Thickness of the surface layer and anisotropy of the surface energy of fullerene

\begin{tabular}{|c|c|c|c|c|c|c|c|}
\hline Fullerene & (hkl) & Structure & $\mathrm{T}_{\mathrm{m}}, \mathrm{K}$ & $\mathrm{M}, \mathrm{g} / \mathrm{mol}$ & $\rho, \mathrm{g} / \mathrm{sm}^{3}$ & $\mathrm{R}(\mathrm{I}), \mathrm{nm}$ & $\begin{array}{c}\begin{array}{c}\sigma_{\mathrm{hkl}} \\
\mathrm{mJ} / \mathrm{m}^{2}\end{array} \\
\end{array}$ \\
\hline \multirow{3}{*}{$\mathrm{C}_{36}$} & 100 & \multirow{3}{*}{$\mathrm{Fd} 3 \mathrm{~m}$} & \multirow{3}{*}{1404} & \multirow{3}{*}{432.40} & \multirow{3}{*}{1.810} & \multirow{3}{*}{$\begin{array}{c}40.61(36) \\
a=11.725 \AA\end{array}$} & 1404 \\
\hline & 110 & & & & & & 1003 \\
\hline & 111 & & & & & & 1652 \\
\hline \multirow{3}{*}{$\mathrm{C}_{60}$} & 100 & \multirow{3}{*}{$\mathrm{Fd} 3 \mathrm{~m}$} & \multirow{3}{*}{2031} & \multirow{3}{*}{720.66} & \multirow{3}{*}{1.484} & \multirow{3}{*}{$\begin{array}{l}85.56(60) \\
a=14.17 \AA\end{array}$} & 2031 \\
\hline & 110 & & & & & & 1451 \\
\hline & 111 & & & & & & 2321 \\
\hline \multirow{3}{*}{$\mathrm{C}_{70}$} & 100 & \multirow{3}{*}{$\mathrm{Fd} 3 \mathrm{~m}$} & \multirow{3}{*}{2260} & \multirow{3}{*}{840.23} & \multirow{3}{*}{1.547} & \multirow{3}{*}{$\begin{array}{l}93.39(64) \\
a=14.96 \AA\end{array}$} & 2260 \\
\hline & 110 & & & & & & 1614 \\
\hline & 111 & & & & & & 2659 \\
\hline \multirow{3}{*}{$\mathrm{C}_{76}$} & 100 & \multirow{3}{*}{$\mathrm{Fd} 3 \mathrm{~m}$} & \multirow{3}{*}{2387} & \multirow{3}{*}{912.84} & \multirow{3}{*}{1.582} & \multirow{3}{*}{98.09} & 2367 \\
\hline & 110 & & & & & & 1705 \\
\hline & 111 & & & & & & 2808 \\
\hline \multirow{3}{*}{$\mathrm{C}_{84}$} & 100 & \multirow{3}{*}{$\mathrm{Fd} 3 \mathrm{~m}$} & \multirow{3}{*}{2547} & \multirow{3}{*}{1008.92} & \multirow{3}{*}{1.589} & \multirow{3}{*}{107.93} & 2547 \\
\hline & 110 & & & & & & 1819 \\
\hline & 111 & & & & & & 2997 \\
\hline \multirow{3}{*}{$\mathrm{C}_{96}$} & 100 & \multirow{3}{*}{$\mathrm{Fd} 3 \mathrm{~m}$} & \multirow{3}{*}{2763} & \multirow{3}{*}{1153.06} & \multirow{3}{*}{1.452} & \multirow{3}{*}{135.00} & 2763 \\
\hline & 110 & & & & & & 1974 \\
\hline & 111 & & & & & & 3251 \\
\hline
\end{tabular}

Nanodiamonds are complex objects, usually with a three-layer structure, including:

- a diamond core with a size of 4-6 nm, which contains from 70 to $90 \%$ of carbon atoms;

- a transitional carbon shell (intermediate layer) around the core of X-ray amorphous carbon structures with a thickness of $0.4-1.0 \mathrm{~nm}$, which can contain from 10 to $30 \%$ of carbon atoms;

- the surface layer, in which, in addition to carbon atoms, other heteroatoms $(\mathrm{N}, \mathrm{O}, \mathrm{H})$ can be located, forming a number of functional groups (all this is at a level of $\sim 8 \mathrm{~nm}$ (compare with Table 1).

Nanodiamonds began to be produced by industry on a large scale and their use is increasing all the time (Figure 6). From Table 2, the thickness of the surface layer of graphite along the $c$ axis is about $1.5 \mathrm{~nm}$ and the number of monolayers is only 2. Along this axis, a monolayer can be created from graphite, turning it into graphene, which can be called "nanographite". The unique electrical properties of graphene (due to its two-dimensional nanostructure), confirmed by numerous studies, are extremely interesting (usually twolayer structures, as in Table 2), both in fundamental and applied terms [28, 29].

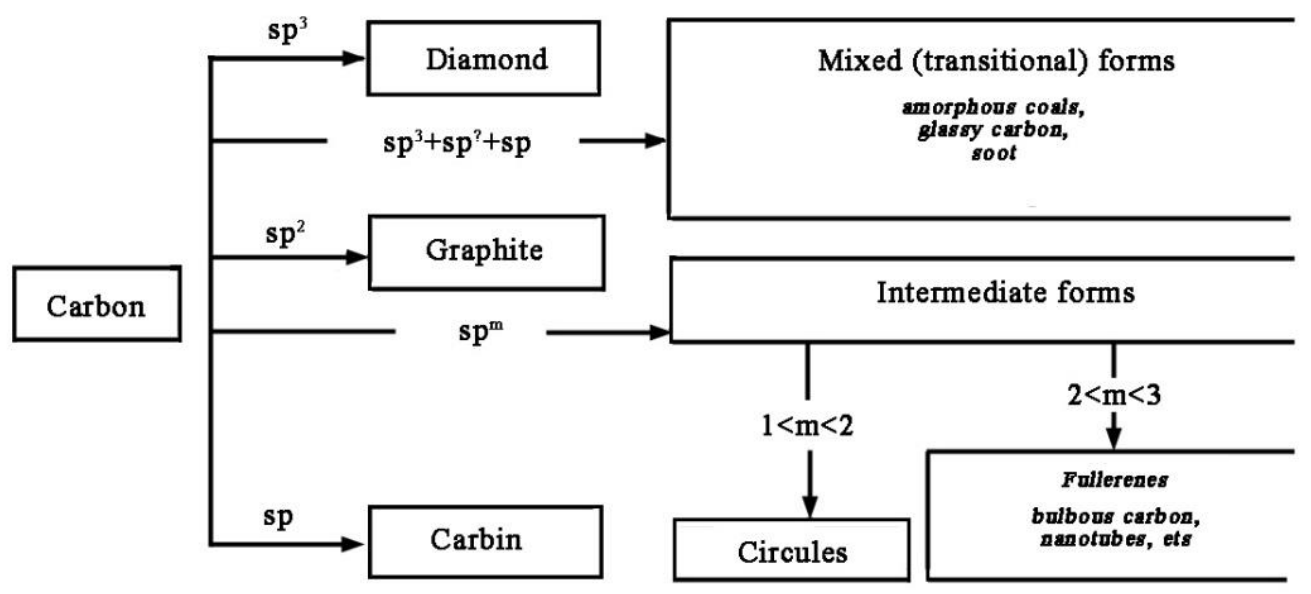

Fig. 5. Classification scheme of allotropic forms of carbon [26]. 


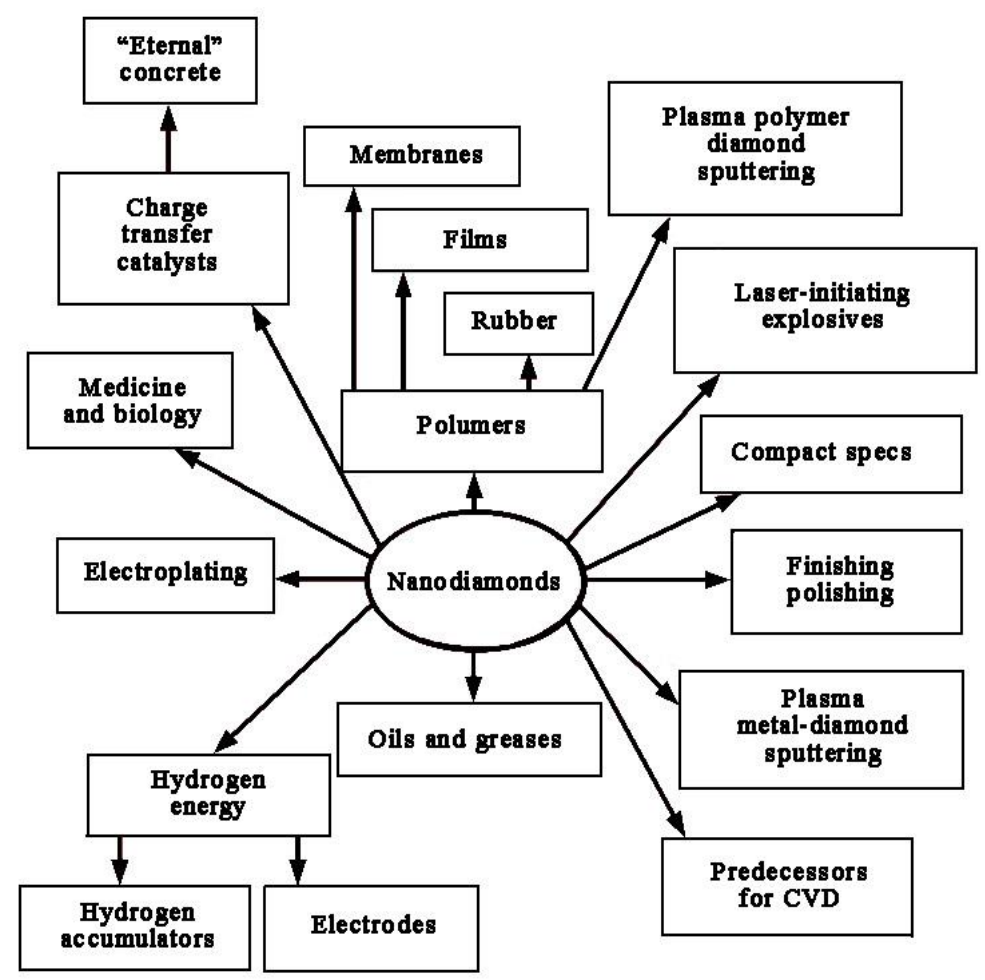

Fig.6. Spheres of application of nanodiamonds [27].

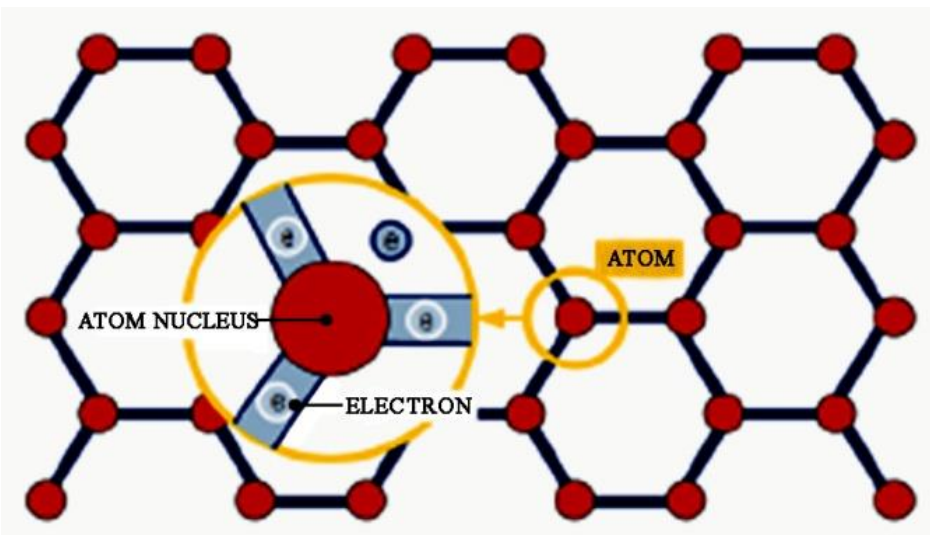

Fig.7. Schematic representation of grapheme.

The amazing properties of graphene are due to the unique nature of its charge carriers - they behave like relativistic particles (Figure 7) [28]. Graphene has a unique structure and exceptional physical and chemical properties, which lead to many possibilities for its application (Fig. 8).

As shown above, the structure of carbyne is formed by carbon atoms assembled into chains by double bonds ( $\alpha$-carbyne) or alternating single and triple bonds ( $\beta$-carbyne). If we imagine that the thickness of the surface layer of carbyne is stretched into a one-dimensional chain along the $c$ axis, then the length of this chain is up to $200 \mathrm{~nm}$ for $\alpha$-carbyne (Table 3). This result was obtained in [30] and is shown in Figure 9.

It turned out that carbyne is the most durable of all known materials. The specific strength of carbine is $6.010^{7}-7.510^{7} \mathrm{~N} \mathrm{~m} / \mathrm{kg}$, while the specific strength of diamond is $2.510^{7}-6.510^{7} \mathrm{~N} \mathrm{~m} / \mathrm{kg}$, graphene is $4.710^{7}-5.510^{7} \mathrm{~N} \mathrm{~m} / \mathrm{kg}$, carbon nanotubes $-4.310^{7}-5.010^{7} \mathrm{~N} \mathrm{~m} / \mathrm{kg}$. Carbyne is the toughest material known. The specific stiffness of carbyne is about $10^{9} \mathrm{~N} \mathrm{~m} / \mathrm{kg}$, which is two times higher than the specific stiffness of graphene $-0.4510^{9} \mathrm{~N} \mathrm{~m} / \mathrm{kg}$. The use of carbine is shown in Figure 10. Fullerenes with a large thickness of the surface layer (Table 4), like rare minerals in nature, are quite rare. Their application in practice is also still limited (Figure 11). 


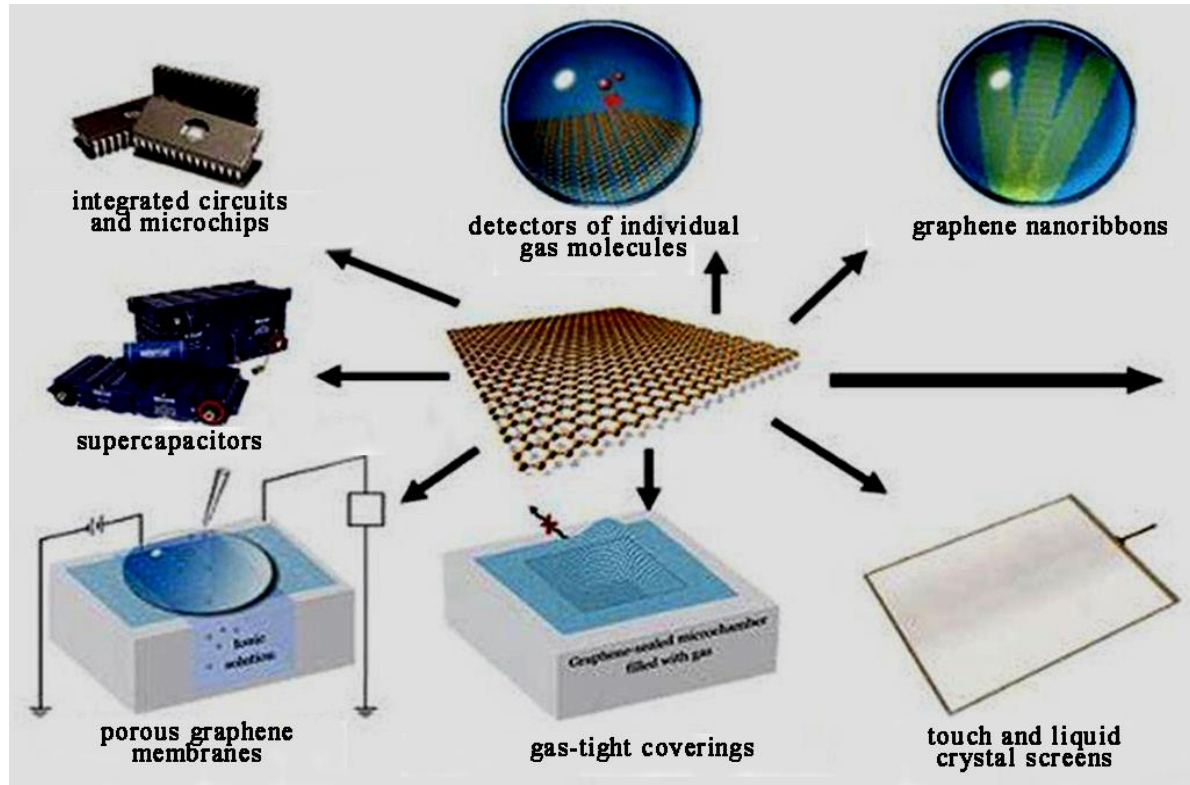

Fig.8. Application of 2D structures of graphite - graphene

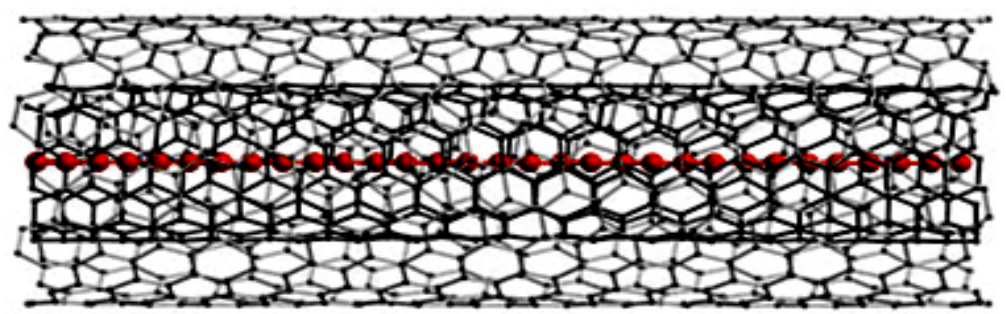

Fig.9. Linear 1D structure of a carbyne molecule (red atoms) inside double-walled carbon nanotubes [30].

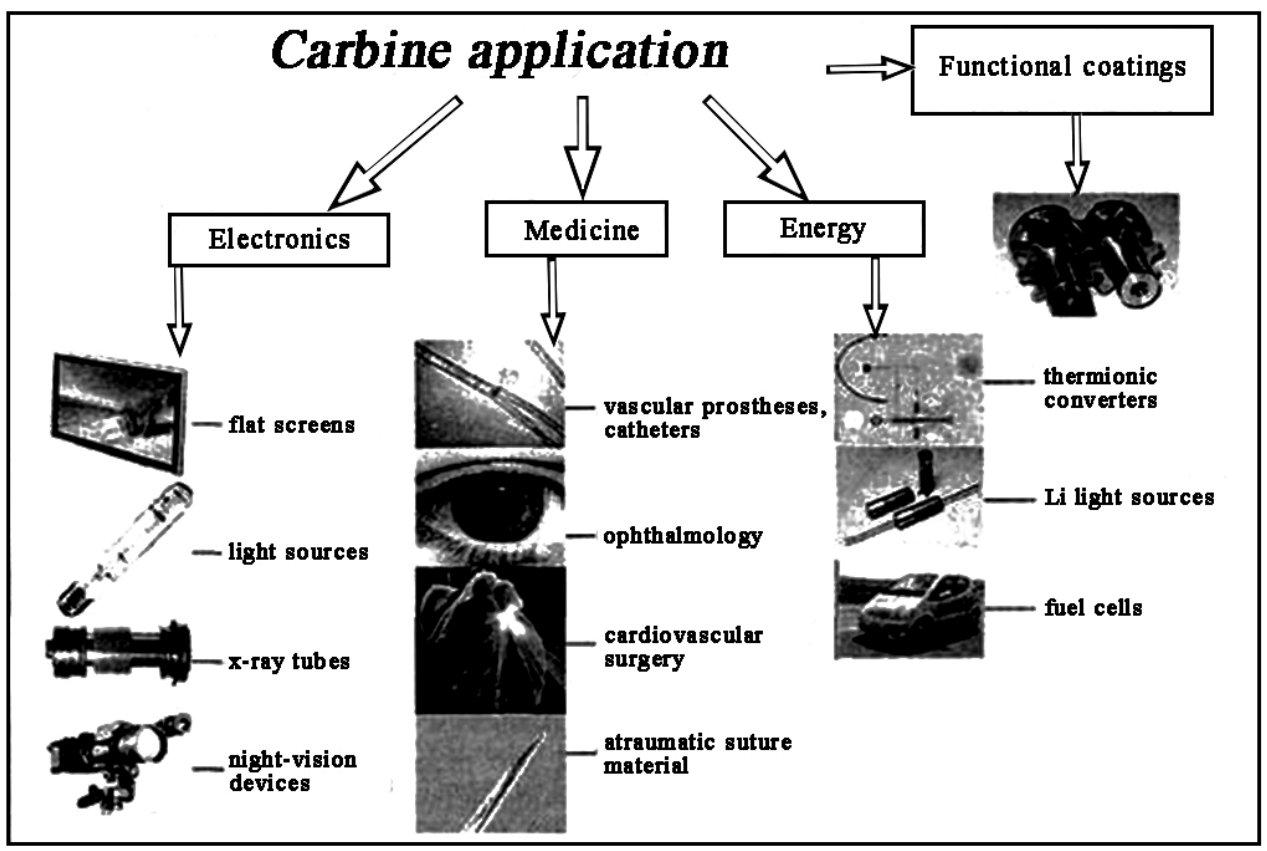

Fig.10. Application of Carbyne nanostructures 

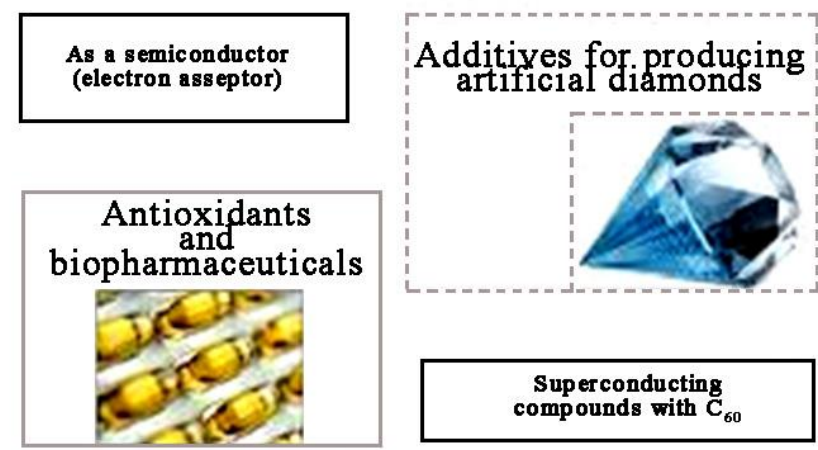

Fig.11. Application of fullerene nanostructures

\section{Conclusion}

Thus, our model of the surface layer showed that the surface of carbon materials is a nanostructure, the properties of which differ significantly from the bulk properties of the material. Currently, in various fields of science, industry and construction, materials are used that are united by dimensional features, namely, nanocrystals, nanoporous materials, nanostructures, and nanocomposites. The range of nanoobjects is extremely wide and continuously increasing, which makes it possible to obtain new catalytic systems in chemistry, engineering materials with unique material science characteristics, structures with nanometer geometry for recording information, converters of various types of energy, superconducting materials in physics, new drugs and their carriers in medicine.

Today, various kinds of materials, the structural elements of which are on the order of millionths of a millimeter, are beginning to be widely used all over the world to provide improved electrical, magnetic, optical and other consumer qualities. Analysis of the state and development trends of the nanoindustry at the present time allows us to conclude that the following types of carbon nanomaterials are the most promising: nanodiamonds, graphene, nanocarbines, fullerenes, which we have considered in detail, as well as soot, amorphous coals, glassy carbons and many other carbon nanomaterials, analysis and calculation of properties of which can be carried out according to the model we have outlined and tested.

\section{Acknowledgments}

The work was carried out under the program of the Ministry of Education and Science of the Republic of Kazakhstan Grant No. 0118RK000063.

\section{REFERENCES}

1 Yurov V.M., Oleshko V.S. The impact of the environment on the contact potential difference of metal machine parts. Eurasian Physical Technical Journal. 2019. Vol.16, No. 1(31), pp. 99 - 108.

2 Yurov V.M., Makeeva O.V., Oleshko V.S., Fedorov A.V. Development of a device for determining work electron output. Eurasian Physical Technical Journal. 2020, Vol.17, No. 1(33), pp. 127 - 131.

3 Yurov V.M., Goncharenko V.I., Oleshko V.S. Anisotropy of the surface of cubic body-centered crystal lattices. Eurasian Physical Technical Journal, 2021, Vol.18, No. 1(35), pp. 9-15.

4 Bochkarev V.P. Development of physical and chemical principles for assessing the effect of surface energy on the properties of materials and processes for microelectronic technology. Dissertation for degree of Doctor of Technical Sciences, Moscow, 2020, 299 p.

5 Yurov V.M., Goncharenko V.I., Oleshko V.S. Anisotropy of surface energy and thickness of the surface layer of magnetic nanostructures. Nano- and microsystem technology, 2021, V. 23, No.2, pp. 8-14.

6 Yurov V.M., Goncharenko V.I., Oleshko V.S. Anisotropy of the surface layer of d - elements. Modern high technologies. 2021, No. 2, pp. 88-93.

7 Orlov Yu.L. Mineralogy of diamond. Moscow: Nauka, 1984, 70 p.

8 Bullakh A.G., Zolotarev A. Atlas of structures of minerals - simple substances, sulfides. St-Petersburg, I997, $28 \mathrm{p}$.

9 Liopo V.A., Ovchinnikov E.V., Sabut A.V., Voznyakovsky A.A. Structural features of diamond nanocrystals. Progressive technologies and systems of mechanical engineering, 2017, No. 1 (56), pp. 73-84.

10 Harkins W. D. Energy Relations of surface of Solids. Journal Chem. Phys., 1942, V. 10, pp. 268-272.

11 Nozhkina A.V., Kostikov V.I. Surface energy of diamond and graphite. Rock-cutting and metal-working tools - technique and technology of its manufacture and application, 2017, No. 20, pp. 161-167. 
12 Ormont B.F.Introduction to physical chemistry and crystal chemistry of semiconductors. Moscow, 1968, $487 \mathrm{p}$.

13 Oshcherin B.N. On surface energies of $\mathrm{A}^{\mathrm{N}} \mathrm{B}^{8-\mathrm{N}}$ semiconducting compounds. Phys. Status Solidi, 1976, A 34, No. 2, pp. K 181-K186.

14 Magomedov M.N. On the surface properties of nanodiamonds. Physics of the Solid State, 2010, Vol. 52, No. 6, pp. $1206-1214$.

15 Zhmurikov E.I., Bubnenkov I.A., Pokrovsky A.S., Kharkov D.V., Dremov V.V., Samarin S.I. Graphite in Science and Nuclear Engineering. Novosibirsk, 2013, 198 p.

16 Kudryavtsev Yu.P., Evsyukov S., Guseva M., Babaev V., Khvostov V. Chemistry and Physics of Carbon: $A$ Series of Advances. New York-Basel-Hong Kong: Marcel Dekker, Inc., 1997, Vol. 25, pp. 1 - 65.

17 Kasatochkin V.I., Savransky V.V., Smirnov B.N., Melnichenko V.M. Study of Carbyne Condensed from Carbon Vapors. DAN SSSR, 1974, Vol. 217, No. 4, pp. $796-799$.

18 Korobova Yu.G., Bazhanov D.I., Khvostov V.V., et al. Effect of hydrogen impurity on the atomic and electronic structure of the crystalline modification of carbyne. VMU. Series 3. Physics. Astronomy. 2013, No. 1, pp. 3744.

19 Zeynalov E.B. Fullerenes: Information Collection (1991-2006). Baku: "Nurlan", 2007, 521p.

20 Kovalenko V.I., Khamatgalimov A.R. Structure and stability of higher fullerenes. Moscow, RAS, 2019,212 p.

21 Shpilevsky E. Fullerenes -new molecules for new materials. Science and Innovation, 2006, No.5(39), pp.3238.

22 Magomedov M.N. About fullerene interaction and properties of fullerites. Thermophysics of high temperatures, 2005, V. 43, No. 3, pp. $385-395$.

23 Yurov V.M., Guchenko S.A., Laurinas V.Ch. Surface layer thickness, surface energy, and atomic volume of an element. Physicochemical aspects of studying clusters, nanostructures and nanomaterials, 2018, Vol. 10, pp. 691699.

24 Gleiter H. Nanostructured materials: basic concepts and microstructure. Acta mater. 2000. V.48, pp. 1 - 29.

25 Borisova P.A. Phase transitions in amorphous fullerenes and their interaction with metals. Dissertation for degree of the Candidate..., Moscow, 2016, 113 p.

26 Romanenko A.V., Simonov P. Carbon materials and their physical and chemical properties. Moscow, 2007, $128 \mathrm{p}$.

27 Dolmatov V.Yu. Detonation nanodiamonds: synthesis, structure, properties and application. Advances in Chemistry, 2007, Vol. 76(4), pp. 375 - 397.

28 Novoselov K.S., Geim A.K., Morozov S.V., Jiang D., Zhang Y., Dubonos S.V., Grigorieva I.V., Firsov A.A. Electric field effect in atomically thin carbon films. Science, 2004, V. 306, pp. $666-669$.

29 Neto A.C., Guinea F., Peres N.M.R., Novoselov K.S., Geim A.K. The electronic properties of grapheme. Rev. Mod. Phys., 2009, Vol. 81. - pp. 109-161.

30 Shi L., Rohringer P., Suenaga K. et al. Confined linear carbon chains as a route to bulk carbyne. Nature Mater. 2016, Vol. 15, pp. 634-639. 